\title{
A humanização do trabalho para os profissionais de enfermagem
}

\author{
Humanization of the work of nursing professionals \\ La humanización del trabajo para los profesionales de enfermería

\section{Simone Coelho Amestoy ${ }^{1}$, Eda Schwartz ${ }^{2}$, Maria Buss Thofehrn $^{3}$}

\section{RESUMO}

Objetivo: conhecer a opinião de profissionais de enfermagem sobre a humanização do processo de trabalho. Métodos: Pesquisa de abordagem qualitativa com dados coletados por meio de entrevistas semi-estruturadas realizadas com sete profissionais de enfermagem da Unidade de Terapia Intensiva da Santa Casa de Misericórdia de Pelotas-RS. Os dados foram analisados através de sucessivas leituras, obtendose duas categorias: humanização do processo de trabalho e lacunas da humanização no processo de trabalho. Resultados: No ambiente hospitalar, a humanização ainda mantém-se enfatizada na figura pessoa-cliente, evidenciando a pouca atenção ao cuidado e à humanização do sujeito-trabalhador. Conclusão: A temática em questão é bastante abordada na literatura, porém, na realidade prática, como envolve mudança de comportamento somente poderá se efetivar mediante a internalização da proposta de humanização pelos sujeitos-trabalhadores das instituições de saúde.

Descritores: Humanização da assistência; Enfermagem; Trabalho/normas

\begin{abstract}
Objective: To describe the perceptions of nursing professionals about humanization of their work process. Methods: A qualitative research approach was used to conduct the study. Data were collected from seven nursing professionals of a Critical Care Unit of the Santa Casa de Misericórdia de Pelotas-RS, through semi-structured interviews. The data were analyzed, through successive readings and content analysis. Two themes have emerged: Humanization of the work process and gaps of the humanization of the work process. Results: In the hospital, the humanization of the work process continues to place emphasis in the person-customer, yet little attention to the care and humanization of the person-worker. Conclusion: Humanization of the work process is widely discussed in literature; however, in practice, it depends on behavioral change and internalization of the need of humanization by the person-worker of health institutions.
\end{abstract}

Keywords: Humanizing of assistance; Nursing; Work/ standards

\begin{abstract}
RESUMEN
Objetivo: conocer la opinión de profesionales de enfermería sobre la humanización del proceso del trabajo. Métodos: Investigación de abordaje cualitativo con datos recolectados por medio de entrevistas semiestructuradas realizadas a siete profesionales de enfermería de la Unidad de Cuidados Intensivos de la Santa Casa de Misericordia de Pelotas-RS. Los datos fueron analizados a través de sucesivas lecturas, que permitieron la construcción de dos categorías: humanización del proceso del trabajo y lagunas de la humanización en el proceso del trabajo. Resultados: En el ambiente hospitalario la humanización aún se enfatiza en la figura de la persona-cliente, quedando evidente la poca atención al cuidado y a la humanización del sujeto-trabajador. Conclusión: Esta temática es muy abordada en la literatura, sin embargo en la realidad práctica como involucra cambio de comportamiento, sólo podrá ser efectivo mediante la interiorización de la propuesta de humanización de los sujetos-trabajadores de las instituciones de salud.

Descriptores: Humanización de la atención; Enfermería; Trabajo/normas

${ }^{1}$ Enfermeira graduada pela Faculdade de Enfermagem e Obstetrícia da Universidade Federal de Pelotas - UFPel - Pelotas (RS), Brasil.

${ }^{2}$ Professora da Faculdade de Enfermagem e Obstetricia da Universidade Federal de Pelotas - UFPel - Pelotas (RS), Brasil.

${ }_{3}^{3}$ Professora da Faculdade de Enfermagem e Obstetrícia da Universidade Federal de Pelotas, Doutora em Enfermagem. Coordenadora do Nepen/UFPel Pelotas (RS), Brasil.
\end{abstract}




\section{INTRODUÇÃO}

O processo de humanização no trabalho da enfermagem é uma questão a ser refletida, pois a maioria dos profissionais enfrenta situações difíceis em seu ambiente de trabalho, tais como baixas remunerações, pouca valorização da profissão e descaso frente aos problemas identificados pela equipe, especialmente quanto ao distanciamento entre o trabalho prescritivo, o preestabelecido institucionalmente e aquele realmente executado junto ao cliente ${ }^{(1)}$.

Assim, ao desenvolver este estudo pretendemos conhecer a percepção da equipe de enfermagem, com vistas ao estímulo para a humanização, na relação intragrupo, visando desenvolver um cuidado de qualidade ao cliente.

O interesse em desenvolver o tema surgiu no decorrer do trabalho em enfermagem, realizado em diversas Unidades de Terapia Intensiva, no qual observamos a dificuldade da equipe de enfermagem em desempenhar um cuidado que atendesse às reais necessidades dos pacientes internados nestas, instigando-nos a compreender o processo de humanização no momento da execução do cuidado terapêutico. Neste estudo, o cuidado terapêutico é entendido como um cuidar diferenciado e profissional, baseado na visão singular, solidária e integradora entre o trabalhador de enfermagem e o cliente.

A relevância do estudo em questão caracteriza-se pelo incentivo à equipe de enfermagem na busca por meios de rompimento dos estereótipos já consolidados em relação ao cuidar, objetivando a promoção da humanização de seu processo de trabalho. A partir do exposto, este estudo teve como objetivo conhecer a opinião dos profissionais de enfermagem sobre a humanização no seu processo de trabalho.

\section{Processo de trabalho da enfermagem}

Compreendemos que o objeto do processo de trabalho da enfermagem é o ser humano enfermo que busca a tarefa profissional, isto é, a execução do cuidado terapêutico pela equipe de enfermagem, a qual conta com ferramentas ou instrumental de trabalho que consistem em meios que visam o alcance da satisfação das necessidades humanas.

Cabe ressaltar que as organizações hospitalares são sistemas complexos, constituídos por diversos setores e profissões, tornando-se instituições formadas por trabalhadores expostos a situações emocionalmente intensas tais como vida, doença e morte, o que freqüentemente desencadeia ansiedade, tensão física e mental ${ }^{(2)}$. Outro fator que tende a agravar essas alterações emocionais encontra-se no fato do trabalho ser executado de forma fragmentada, o que intensifica a lacuna existente entre as ações desenvolvidas pelos profissionais, pois neste trabalho identifica-se uma compartimentação da pessoa a ser cuidada ${ }^{(3)}$.

De modo geral, pode-se afirmar que estão ocorrendo alterações no mundo do trabalho, estas têm vindo de encontro a amenizar o desgaste da saúde dos trabalhadores, decorrente dos sentimentos de impotência frente à estrutura hierárquica, geralmente centralizadora, além de abrandar as situações de alienação e estagnação em que os profissionais se encontram, pois foram jogados numa estrutura de trabalho que ainda valoriza mais os meios tecnológicos e a execução de tarefas padronizadas e rotinizadas, em detrimento da singularidade dos clientes $^{(4)}$.

Frente ao exposto, nos deparamos com a dimensão da subjetividade do trabalhador, a qual enfatiza o entendimento do ser humano, de seus conflitos, de seus vínculos consigo mesmo e com a família no próprio ambiente de trabalho e a interação com os demais membros da equipe ${ }^{(5)}$. Quanto ao cuidado de si, a preocupação é com o autocuidado do profissional, que ocorre a partir da sua conscientização dos costumes e hábitos para o bem-estar físico, emocional e social ${ }^{(6)}$.

\section{Humanização: um caminho a ser percorrido}

O Ministério da Saúde implantou, no ano 2000, o Programa Nacional de Humanização da Assistência Hospitalar e, posteriormente, a Política Nacional de Humanização, visando atender às demandas subjetivas manifestadas pelos usuários e trabalhadores dos serviços de saúde, baseando-se na integralidade da assistência ${ }^{(7)}$. A humanização do atendimento em saúde subsidia o atendimento, a partir do amparo dos princípios predeterminados como: a integralidade da assistência, a eqüidade e o envolvimento do usuário, além de favorecer a criação de espaços que valorizem a dignidade do profissional e do paciente ${ }^{(8)}$.

\section{MÉTODOS}

O estudo, de natureza descritiva e exploratória, foi realizado com utilização da abordagem qualitativa para o tratamento dos dados. O mesmo foi realizado durante os meses de setembro e outubro de 2005 na Unidade de Terapia Intensiva Geral da Santa Casa de Misericórdia da cidade de Pelotas-RS, composta por dez leitos, com quadro de pessoal formado por 25 profissionais de enfermagem, sendo 5 enfermeiros, 8 técnicos e 12 auxiliares de enfermagem.

Os sujeitos do estudo foram sete profissionais de enfermagem que trabalhavam na unidade citada. Os participantes que fizeram parte dessa pesquisa preencheram os seguintes critérios: tinham vínculo empregatício com a instituição; concordaram em 
participar do estudo proposto; permitiram que a entrevista fosse gravada e que, após a análise dos dados, os resultados fossem divulgados nos meios científicos. Os mesmos foram identificados com nomes fictícios correspondentes a personagens dos clássicos da literatura brasileira, para garantir o anonimato.

O estudo seguiu os procedimentos éticos exigidos pela Resolução no 196/96 ${ }^{(9)}$ do Conselho Nacional de Saúde do Ministério da Saúde; foi aprovado pelo Comitê de Ética da Faculdade de Medicina da Universidade Federal de Pelotas e pela instituição de trabalho dos entrevistados, os quais assinaram o Termo de Consentimento Livre e esclarecido. As entrevistas foram realizadas em encontros individuais no próprio local do estudo, utilizando-se um roteiro semi-estruturado sendo feita pelas autoras da pesquisa.

Os dados coletados foram analisados à partir do agrupamento das idéias, elementos e manifestações ao redor de uma temática capaz de estabelecer uma classificação ${ }^{(10)}$, obtendo-se duas categorias: humanização do processo de trabalho e lacunas da humanização do processo de trabalho.

\section{RESULTADOS}

Categoria I-Humanização do processo de trabalho

A humanização do ambiente de trabalho é um subproduto da necessidade de incorporar o amor nas relações profissionais e interpessoais; é a administração dos ressentimentos ${ }^{(11)}$. Entendida, ainda, como a capacidade de se colocar no lugar do outro, a equipe passa a cuidar o cliente com respeito e dignidade ${ }^{(12)}$. Esse modo de olhar para a humanização no trabalho foi identificado nas falas a seguir:

"Humanização é quando uma pessoa que está precisando de ajuda e tu te oferecer, engloba: ajudar as pessoas, entender o lado do outro, tentar te por no lugar dos outros, solidariedade". (Iracema)

"É tu olhar para o outro e te posicionar no lugar dele e não querer nada de ruim para o paciente". (Ana Terra)

Percebemos que alguns entrevistados encontram-se sensibilizados quanto à compreensão do conceito "humanizar". No ambiente hospitalar, notamos que a humanização está muito enfatizada na figura pessoacliente, e ainda disponibiliza pouca atenção ao cuidado e a humanização do sujeito-trabalhador, conforme as verbalizações a seguir:

'Para nós está meio complicado (...) cada vez mais somos cobrados, a instituição muda o processo de trabalho e sobrecarrega a enfermagem (...) direitos temos poucos". (Bibiana)

Ao refletir sobre humanização no âmbito institucional, primeiramente pensamos nos usuários e, apesar de muito discutir-se sobre a humanização hospitalar, o bem-estar dos profissionais da saúde tem sido deixado em segundo plano $^{(2)}$.

Quanto à humanização do processo de trabalho, a maioria respondeu que a instituição, por possuir uma equipe de humanização, possibilita encontros entre os trabalhadores, visando tanto o aprendizado, quanto o crescimento intelectual. Mesmo com as tentativas da organização hospitalar no sentido de aprimorar as relações interpessoais nas equipes, as respostas que mais se sobressaíram estavam relacionadas à desvalorização do sujeito-trabalhador.

"Hoje temos um pouco mais de autonomia, porém falta conscientização da valorização da enfermagem, nós trabalhamos vinte e quatro horas em contato com os pacientes, eles não valorizam que a gente está ligado com os pacientes e a família". (Bibiana)

"Para gente passar humanização para os pacientes a gente precisa se sentir bumanizado". (Macunaima)

Cabe ressaltar que, apesar da existência da equipe de humanização, seria pertinente uma avaliação desse serviço com vista a atender, de forma mais objetiva, os anseios dos trabalhadores uma vez que, as ações atualmente realizadas por essa equipe, já se tornaram visíveis na empresa.

Assim, o agir dessa equipe pode tornar-se mais eficiente e eficaz, especialmente quanto ao aumento da auto-estima dos profissionais da enfermagem, para favorecer a ocupação de uma posição de reconhecimento, prestígio e autonomia profissional ${ }^{(5)}$. Percebemos, ainda, pelas respostas obtidas, que a maioria dos profissionais considera o não-envolvimento emocional como uma maneira de cuidar de si, ou seja, quanto mais íntima a relação paciente-enfermeiro, mais propício o profissional está a compartilhar os sentimentos com o paciente. Então, como uma estratégia de defesa, ele reduz o contato com o doente, evitando o envolvimento emocional ${ }^{(13)}$.

Os estudos, porém, nos alertam para a necessidade de articular as ações realizadas pela equipe de enfermagem, mediante uma interação dos sujeitos trabalhadores em que, além das intervenções técnicas, estejam entrelaçados a prática comunicativa pela busca do reconhecimento e o entendimento mútuo para o alcance da tarefa profissional, em conformidade com a necessidade dos clientes ${ }^{(14)}$.

Esses conflitos, que podem causar inclusive um distanciamento do profissional com o paciente, são decorrentes do encontro entre o trabalhador com sua história de vida e condições de trabalho, muitas vezes fixadas independentemente do interesse e vontade desta pessoa, e aponta que faz-se necessário identificar, no 
trabalhador, as relações existentes entre o que ele revela, visualiza, manifesta e o que é construído mediante os seus sentimentos. Há, então, a necessidade de reforçar os sentimentos de solidariedade, de formação da identidade e originalidade de cada trabalhador com vistas às relações de aceitação no grupo, já que a habilidade emocional, o envolver-se, são consideradas como uma hierarquia superior, em comparação às habilidades técnicas ${ }^{(1)}$.

"Procuro deixar aqui no hospital o que está aqui no men serviço, já não me envolvo emocionalmente com os problemas dos pacientes é uma auto defesa emocional, anticorpo, pois senão é tu que acaba adoecendo". (Anita)

"Eu até me envolvo quando o paciente é muito jovem, mas emocionalmente tento não me envolver muito, me envolvo mas até ali". (Bibiana)

Mediante o constatado por essas falas é preciso rever a habilidade emocional de tal equipe, pois o contato com o paciente nunca ocorre de forma neutra, pois sempre carregamos nossos valores culturais, preconceitos ou atitudes, portanto, cuidar de quem cuida é essencial para que possa cuidar terapeuticamente dos outros $^{(15)}$. Outros acreditam, porém, que o uso de equipamentos de proteção individual (EPIs) é uma forma de estar cuidando de si. Neste aspectO, destacamos as seguintes falas:

"Acho importante o cuidado de si, principalmente para pacientes contaminados, se eu não usar luvas e lavar as mãos eu posso contaminar minha familia". (Macunaima)

"Protejo-me, no meu trabalho, usando equipamentos de proteção individual e lavando as mãos, vou me proteger e proteger o paciente". (Bibiana)

O ambiente hospitalar contribui, não apenas para a ocorrência de acidentes de trabalho, no qual os EPIs são importantes, mas especialmente leva ao aparecimento de situações de estresse ocupacional e, também, de fadiga física e mental ${ }^{(2)}$.

Assim, vislumbramos a humanização do trabalho a partir da capacitação da habilidade emocional do profissional para o enfrentamento da dimensão da subjetividade, de modo a criar alternativas para superação das frustrações presentes no ambiente de trabalho.

\section{Categoria II-Lacunas da humanização do processo de trabalho.}

Identificamos a existência de lacunas na humanização do processo de trabalho dos profissionais da enfermagem. Conforme os relatos a seguir, fica evidente que as condições materiais na instituição interferem nos sentimentos dos trabalhadores, dificultando a humanização na assistência de enfermagem.

"Deveria melhorar em equipamentos". (Bibiana)

"Também é fundamental trabalhar com uma aparelhagem boa e de qualidade". (Macunaima)

Entretanto, é preciso estar atento ao fato de que, mesmo em instituições detentoras de equipamentos modernos, permanece a necessidade de profissionais que desenvolvam as habilidades emocionais, e que sejam capazes de sensibilizar-se com as situações vivenciadas em seu cotidiano, evitando prestar um cuidado tecnicista, mas preparados para oferecer um cuidado com compaixão ao cliente, sem exploração, domínio ou desconfiança. Uma compaixão amorosa que permita sermos tão humanos quanto possível, tão envolvidos quanto o sentimento determine ${ }^{(16)}$.

A segunda lacuna expõe o descontentamento da equipe em relação às propostas institucionais quanto à humanização.

"A instituição fala muito sobre bumanizaçãa, mas o funcionário não é atendido". (Capitu)

"O regime é de quartel, não pode se atrasar, tudo funciona por memorandos, éfuncionante, mas como um regime, deve se ter regras, é obrigado a ter, mas não precisaria ser tão rigoroso". (Ana Terra)

O serviço de enfermagem, como um grupo organizado de pessoas, no qual é grande o número e a diversidade das atividades, muitas vezes apresenta um trabalho normativo que corresponde a regras institucionais, o que pode dificultar a capacidade de inovação e adaptação dos profissionais a novas situações e mudanças do ambiente, pois o trabalho normativo se distancia muito do trabalho executado realmente ${ }^{(5)}$.

Alguns funcionários, mesmo identificando as dificuldades apontadas por seus parceiros de equipe, vislumbram a realidade mediante outra ótica, ou seja, da compreensão, da flexibilidade, do entendimento, do comportamento e funcionamento em grupos de trabalho.

"Estou satisfeita com men trabalho, gosto do que faço, gosto do setor e da equipe, pra mim a instituição é boa". (Iracema)

"Com todas as queixas e pontos negativos os funcionários acreditam que seja ainda a melhor instituição de Pelotas para trabalhar". (Bibiana)

O trabalho é fundamental, devendo ser encarado como fonte de prazer e satisfação e não de sofrimento; por isso, além das mudanças internas nos trabalhadores, são necessárias, concomitantemente, alterações no ambiente de trabalho e nas relações interpessoais que 
deveriam estar baseadas no amor ao próximo, para que a humanização possa se tornar uma realidade no cotidiano $^{(11)}$.

\section{CONSIDERAÇÕES FINAIS}

Percebemos, através dos relatos de alguns profissionais, que os mesmos são benevolentes e atenciosos com os pacientes. Apesar do sistema desgastante e da carga de sofrimento psíquico, conseguem manter e demonstrar suas emoções, ou seja, com o compromisso de oferecer um cuidado fundamentado na expressão do amor, ternura, cordialidade e compaixão.

Gostaríamos de chamar a atenção para o fato de que outros profissionais ainda não compreendem, claramente, a humanização do processo de trabalho e sentem-se pouco valorizados dentro do ambiente hospitalar. Isso pode estar ocorrendo por tratar-se de um tema novo, abordado há pouco tempo nas instituições de saúde, já que até então, a ênfase nas escolas de enfermagem estava no modelo biomédico, isto é, no processo saúde-doença, com base num currículo fragmentado em que o ser humano é visto como peças de uma máquina. Assim, sem preparo adequado, os trabalhadores da enfermagem, na maioria das vezes, apresentam sentimentos de impotência, o que dificulta o desenvolvimento de ações humanizadoras no contexto das organizações de saúde.

$\mathrm{O}$ uso dos EPIs e o não envolvimento emocional com os pacientes e familiares foi lembrado pelos participantes da pesquisa como uma forma de realizar o cuidado de si próprias, acreditando que, ao agirem dessa maneira, diminuem as chances de sofrimento no ambiente de trabalho, o que não condiz com as recomendações bibliográficas, que reforçam a importância do envolverse como modo de expressar amizade e solidariedade. As instituições hospitalares encontram-se dependentes dos recursos tecnológicos devido ao seu surpreendente desenvolvimento ao nível mundial, porém, o uso de tais recursos pode levar a um cuidado mais frio e impessoal. Tal forma de cuidado pode ser amenizada pela capacitação contínua da habilidade emocional do trabalhador.

Outro fato importante constatado foi o descontentamento dos trabalhadores em relação aos padrões rígidos e, muitas vezes, autoritários, adotados pela empresa. Esta situação vem sendo modificada pela incrementação do Programa de Humanização Hospitalar, cujo enfoque está na implantação de uma cultura humanista e democrática, na qual todos os trabalhadores precisam ser ouvidos, o que favorece a valorização do ser humano.

Como já foi mencionada, a temática em questão é bastante abordada na literatura, entretanto, na realidade prática, envolve mudança de comportamento e, mesmo os trabalhadores estando conhecedores da importância deste programa, os resultados aparecem apenas após a internalização da proposta de humanização na instituição, por todos os profissionais.

Assim, a atuação da equipe de humanização no ambiente hospitalar, apesar de constituir um trabalho lento, é preciso que mantenha sua trajetória, pois acreditamos que, mediante a capacitação e avaliação contínuas de suas ações, desencadeado, aos poucos, um processo de conscientização dos trabalhadores para essa nova forma de vivenciar o ambiente trabalho, na qual cada profissional deva conseguir ofertar envolvimento, amor e compaixão ao cliente.

\section{REFERÊNCIAS}

1. Dejours C, Abdoucheli E. Itinerário teórico em psicopatologia do trabalho. In: Dejours C, Abdoucheli E, Jayet C. Psicodinâmica do trabalho: contribuições da Escola Dejouriana à análise da relação prazer, sofrimento e trabalho. São Paulo: Atlas; 1994. p.119-45.

2. Martins MCA. Situações indutoras de stress no trabalho dos enfermeiros em ambiente hospitalar Millenium. Res ISPU[periódico na Internet] 2003 [citado 2005 Nov 11];28 Out:[cerca de 16p.]. Disponível em http://www.ipv.pt/ millenium/Millenium 28/18.htm.

3. Leopardi MT. O processo de trabalho em saúde: organização e subjetividade. Florianópolis: Papa-Livros; 1999.

4. Santos BS. A crítica da razão indolente: contra o desperdício da experiência. São Paulo: Cortez; 2000.

5. Thofehrn MB. Vínculos profissionais: uma proposta para o trabalho em equipe na enfermagem [tese]. Florianópolis: Universidade Federal de Santa Catarina; 2005.

6. Lunardi VL. A ética como o cuidado de si e o poder pastoral na enfermagem. Pelotas (RS): Editora da UFPel; 1999.

7. Brasil. Ministério da Saúde. Secretaria Executiva. Núcleo Técnico da Política Nacional de Humanização. Brasília (DF): Ministério da Saúde, 2004.

8. Casate JC, Corrêa AK. Humanização do atendimento em saúde: conhecimento veiculado na literatura brasileira de enfermagem. Rev Latinoam Enfermagem. 2005; 13(1): 10511.

9. Brasil. Ministério da Saúde. Conselho Nacional de saúde. Normas de pesquisa envolvendo seres humanos - Res. CNS 196/96. Bioética. 1996; 4(2 Supl): 15-25.

10. Minayo MCS. Pesquisa social: teoria, método e criatividade. Petrópolis: Vozes; 2000.

11. Rodrigues AL. Saúde, amor e trabalho. In: Silva MAD. Quem ama não adoece: o papel das emoções na prevenção e cura das doenças. São Paulo: Best Seller; 2001. p.309-21.

12. Vila VSC, Rossi LA. O significado cultural do cuidado humanizado em unidade de terapia intensiva: muito falado e pouco vivido. Rev Latinoam Enfermagem. 2002; 10(2): 137-44.

13. Pitta A. Hospital: dor e morte como ofício. 4a ed. São Paulo: Hucitec; 1999.

14. Peduzzi M, Ciapone MHT. Trabalho em equipe e processo grupal. In: Kurcgant P, coordenadora. Gerenciamento em enfermagem. Rio de Janeiro: Guanabara Koogan; 2005. p. $108-24$. 
15. Silva MJP. Humanização em Unidade de Terapia Intensiva. In: Cintra EA, Nishide VM, Nunes WA, organizadoras. Assistência de enfermagem ao paciente gravemente enfermo. São Paulo: Atheneu; 2001. p.1-11.

16. Leopardi, MT. Entre a moral e a técnica: ambigüidades do cuidado de enfermagem. Florianópolis: Editora da UFSC; 2004. 